Artículos científicos

\title{
Clasificación de frutos del durazno en maduros, no maduros y dañados hacia la cosecha automatizada
}

Classification of Peach Fruits in Ripe, Unripe and Damaged Towards

Automated Harvest

Classificação de frutos de pêssego em maduros, imaturos e danificados para colheita automatizada

Ma. Dolores Arévalo Zenteno

Universidad Autónoma del Estado de México, Centro Universitario UAEM Texcoco,

México

mdarevaloz@uaemex.mx https://orcid.org/0000-0002-4615-6890

José Sergio Ruiz Castilla

Universidad Autónoma del Estado de México, Centro Universitario UAEM Texcoco,

México

jsruizc@uaemex.mx https://orcid.org/0000-0001-7821-4912

Joel Ayala de la Vega

Universidad Autónoma del Estado de México, Centro Universitario UAEM Texcoco,

México

jayalad408@uaemex.mx https://orcid.org/0000-0003-3279-4143 


\section{Resumen}

A partir de la tecnología de visión artificial, específicamente de redes neuronales convolucionales, se propuso una solución para realizar el reconocimiento de frutos de durazno maduros, así como la identificación de frutos dañados. La finalidad es obtener frutos con el nivel de calidad adecuado para su comercialización. Para lograr este propósito, se obtuvieron imágenes de duraznos en un ambiente no controlado. Se recortaron las imágenes digitales hasta obtener el área de interés. Se configuraron tres conjuntos de datos: el primero, de duraznos maduros e inmaduros; el segundo, también de duraznos maduros e inmaduros pero con enfoque en un área textural, y el tercero, de duraznos sanos y dañados. Se aplicó una red neuronal convolucional, que fue programada en el lenguaje Python, las librerías de Keras y TensorFlow. Durante las pruebas se obtuvo una precisión de $95.31 \%$ a la hora de elegir entre maduros y no maduros. Mientras que al clasificar los duraznos sanos y dañados se obtuvo $92.18 \%$ de precisión. Por último, al clasificar las tres categorías (dañados, inmaduros y maduros), se obtuvo $83.33 \%$ de precisión. Los resultados anteriores indican que con inteligencia artificial embebida en un dispositivo físico se puede hacer la clasificación del fruto del durazno.

Palabras clave: durazno, red neuronal convolucional, visión artificial.

\section{Abstract}

Using computer vision technology, specifically convolutional neural networks, a solution was proposed to perform the recognition of ripe peach fruits, as well as the identification of damaged fruits. The purpose is to obtain fruits with the appropriate level of quality for their commercialization. To achieve this purpose, images of peaches were obtained in an uncontrolled environment. Digital images were cropped until the area of interest was obtained. Three data sets were configured: the first, for ripe and unripe peaches; the second, also of ripe and unripe peaches but only focused on a textural area, and the third, of healthy and damaged peaches. A convolutional neural network was applied, which was programmed in the Python language, the Keras and TensorFlow libraries. During the tests, a precision of $95.31 \%$ was obtained when choosing between mature and immature. While when classifying healthy and damaged peaches, $92.18 \%$ accuracy was obtained. Finally, when classifying the three categories (damaged, immature and mature), $83.33 \%$ precision was 
obtained. The previous results indicate that with artificial intelligence embedded in a physical device, the classification of the peach fruit can be done.

Keywords: peach, convolutional neural network, computer vision.

\section{Resumo}

Utilizando tecnologia de visão artificial, especificamente redes neurais convolucionais, foi proposta uma solução para realizar o reconhecimento de frutos de pêssego maduros, bem como a identificação de frutos danificados. O objetivo é obter frutas com o nível de qualidade adequado para sua comercialização. Para tanto, imagens de pêssegos foram obtidas em ambiente não controlado. As imagens digitais foram recortadas até que a área de interesse fosse obtida. Três conjuntos de dados foram configurados: o primeiro, para pêssegos maduros e verdes; a segunda, também de pêssegos maduros e verdes, mas com foco em uma área textural, e a terceira, de pêssegos saudáveis e danificados. Foi aplicada uma rede neural convolucional, que foi programada na linguagem Python, nas bibliotecas Keras e TensorFlow. Durante os testes, obteve-se uma precisão de 95,31\% na escolha entre maduro e imaturo. Ao classificar pêssegos saudáveis e danificados, obteve-se 92,18\% de acerto. Por fim, ao classificar as três categorias (danificado, imaturo e maduro), obteve-se 83,33\% de precisão. Os resultados anteriores indicam que com inteligência artificial embutida em um dispositivo físico, a classificação do pêssego pode ser feita.

Palavras-chave: pêssego, rede neural convolucional, visão computacional.

Fecha recepción: Julio 2020

Fecha aceptación: Diciembre 2020 


\section{Introducción}

\section{Fruto de durazno}

El fruto del duraznero es una fruta de alto consumo. Además de tener un sabor dulce y un aroma delicado, se caracteriza por ser de color amarillo, rojo, rosa o una combinación de estos, tener un tamaño de $4 \mathrm{~cm}$ a $8 \mathrm{~cm}$ de diámetro, contar con un surco longitudinal marcado y con un mesocarpo muy carnoso. Precisamente por estas características, es ampliamente cultivado para su comercialización y utilizado de diversas formas en el arte culinario. El durazno, también conocido como melocotón, es consumido como fruta fresca, aunque igualmente se puede procesar para obtener otros productos agroindustriales. Para lograr una cosecha de duraznos de calidad, y con ello un margen de ganancia para los productores, estos deberán organizar y programar las épocas de producción en cada región, así como planear la distribución de la fruta en los centros de consumo de manera regulada para evitar que la oferta sea mayor que la demanda. Por último, no hay que olvidar la utilización de nuevas variedades que, además de contar con las características idóneas de calidad, permiten ampliar las épocas de maduración y cosecha (Baíza, 2004).

Independientemente de la región, la fruta se deberá cosechar cuando el color de la pulpa cambie de color verde a amarillo claro. Con ello se logra que el fruto tenga mayor peso y un sabor óptimo y, por lo tanto, mayor ganancia para el productor. Por el contrario, si se cosecha ya madura, se lastima más fácil y se pudre rápidamente.

\section{Trabajos relacionados}

Alipasandi, Ghaffari y Zohrabi (2013) introdujeron técnicas de extracción de características de color para clasificar tres variedades del fruto del durazno en maduro e inmaduro. Los autores concluyeron que estas tienen un efecto más significativo que las características de forma en términos de clasificación. Otros trabajos se han enfocado en desarrollar sistemas de identificación a través de las hojas de los árboles y las plantas (Cervantes et al., 2017; Kadir, Nugroho, Susanto e Insap, 2011). Por ejemplo, Hati y Sajeevan (2013) recurrieron a técnicas de procesamiento de imagen para extraer características geométricas de las hojas: relación de aspecto, relación de ancho, ángulo de vértice, relación de vértice, ángulo de la base, relación de momento y circularidad. El desarrollo de una aplicación con java condujo a una precisión de reconocimiento de $92 \%$. 
Revista Iberoamericana de las Ciencias Biológicas y Agropecuarias

La aportación de este trabajo fue, precisamente, la extracción de características. Posteriormente, Amlekar, Manza, Yannawar y Gaikwad (2014) descubrieron que patrones biométricos como el patrón de venación hacen las labores de clasificación más sencillas. Dos modelos fueron utilizados para evaluar su precisión: el llamado vecino más cercano y la red neuronal de retropropagación. Los resultados indicaron mayor precisión en la red neuronal.

\section{Redes neuronales convolucionales}

Los trabajos de investigación con redes neuronales convolucionales ( $\mathrm{CNN}$, por sus siglas en inglés) han avanzado en los últimos años. Algunos de los esfuerzos relacionados con $\mathrm{CCN}$ han estado orientados a probar modificaciones en la arquitectura. En esa línea, Simonyan y Zisserman (2015) presentaron seis diferentes configuraciones de red cambiando la profundidad de las capas convolucionales, insertando la no linealidad, forzando a una regularización y decrementando el número de parámetros en la pila de capas. Y analizaron el efecto de la profundidad de la CNN en la configuración de reconocimiento de imagen a gran escala. Se trató de una evaluación exhaustiva de las redes de gran profundidad utilizando una arquitectura con filtros de convolución de $3 \times 3$. Al final, lograron demostrar que se puede lograr una mejora significativa en las configuraciones de la técnica anterior al aumentar la profundidad hasta 19 capas y requiriendo menos épocas para coincidir.

Por su parte, Morris (2018) diseñó una CNN para discriminar los límites de las hojas. Además, usando estas predicciones de límite, propuso un método para generar segmentaciones de hoja de límite cerrado. Mientras que Sharpe (2019) analizó el comportamiento de tres CNN: DetectNet, VGGNet y GoogLeNet para detectar maleza de Geranium carolinianum en cultivos de fresa. La meta era ayudar a los productores de fresa a aplicar herbicida solo a la maleza. Las fotos fueron tomadas con cámara digital. GoogLeNet y VGGNet no tuvieron mucho éxito durante la validación con imágenes. El entrenamiento de la CNN con imágenes recortadas aumentó la detección de Geranium carolinianum durante la validación para VGGNet (77 \%) y GoogLeNet (62 \%). DetectNet, entrenado con hojas de Geranium carolinianum, logró la precisión más alta (94 \%) para la detección de plantas durante la validación, por lo que fue la prueba CNN más viable para la detección remota basada en imágenes de Geranium carolinianum en competencia con la fresa. Sharpe (2019) sugiere, para investigaciones futuras, identificar el enfoque óptimo para 
la detección in situ e integrar la tecnología de detección con un pulverizador de precisión. En suma, el uso de DetectNet como el sistema de decisión para un subsistema de visión artificial basado en cámara digital parece una opción viable para el control de precisión de Geranium carolinianum en la producción de fresas de Florida.

Los trabajos de Ma et al. (2018), Heyan, Qinglin y Yuankai (2018) y Krizhevsky, Sutskever y Hinton (2012) son otros ejemplos de la capacidad de las CNN con gran profundidad para extraer rasgos discriminatorios a partir exclusivamente de imágenes de plantas.

\section{Materiales y método}

\section{Conjunto de datos imágenes digitales}

Las imágenes fueron tomadas con una cámara profesional Nikon d3500 de 24.2 megapíxeles con los lentes AF-P DX Nikkor 18 mm-55 mm y el AF-P DX Nikkor 70 mm$300 \mathrm{~mm}$. Luego de la toma, las imágenes se recortaron hasta dejar solo el área de interés: por un lado, duraznos completos; por el otro, considerando únicamente la textura. Finalmente, se hicieron conjuntos de imágenes con duraznos maduros e inmaduros, sanos y dañados. Los grupos de imágenes se pueden ver en la figura 1. 
Figura 1. El conjunto de datos de imágenes digitales de frutos: $a$ ) maduros e inmaduros, $b$ ) maduros e inmaduros (textura) y $c$ ) sanos y dañados
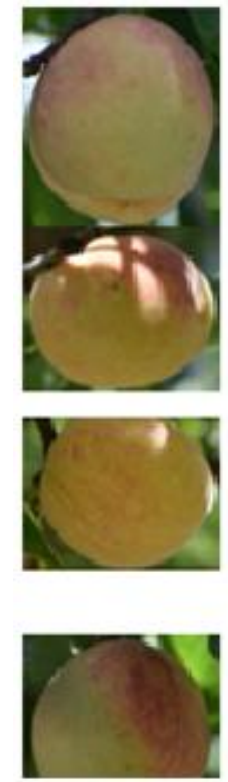
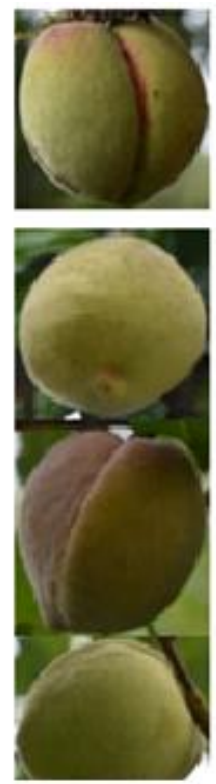
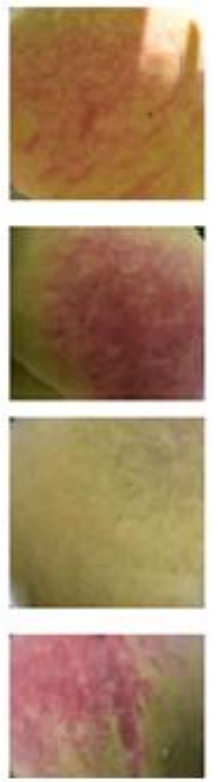

Fuente: Elaboración propia
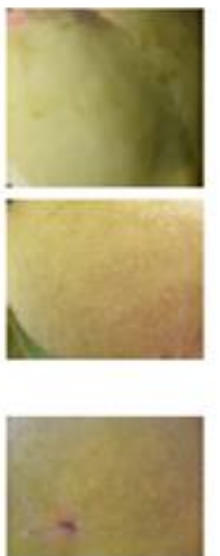
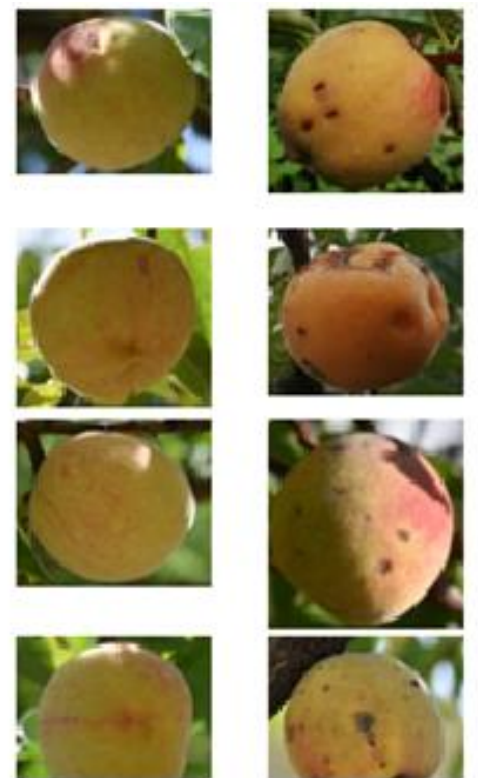

Los conjuntos de imágenes de duraznos maduros, inmaduros, sanos y dañados para los tres escenarios se detallan en la tabla 1.

Tabla 1. Cantidad de imágenes para cada conjunto de datos de imágenes digitales.

\begin{tabular}{|l|l|l|l|l|l|}
\hline $\begin{array}{l}\text { Durazno } \\
\text { completo }\end{array}$ & $\begin{array}{l}\text { Duraznos } \\
\text { maduros e } \\
\text { inmaduros }\end{array}$ & $\begin{array}{l}\text { Área de } \\
\text { textura }\end{array}$ & Cantidad & $\begin{array}{l}\text { Durazno } \\
\text { completo }\end{array}$ & Cantidad \\
\hline $\begin{array}{l}\text { Maduros } \\
\text { entrenamiento }\end{array}$ & 160 & $\begin{array}{l}\text { Maduros } \\
\text { entrenamiento }\end{array}$ & 200 & $\begin{array}{l}\text { Sanos } \\
\text { entrenamiento }\end{array}$ & 320 \\
\hline $\begin{array}{l}\text { Maduros } \\
\text { validación }\end{array}$ & 40 & $\begin{array}{l}\text { Maduros } \\
\text { validación } \\
\text { entrenamiento }\end{array}$ & 40 & $\begin{array}{l}\text { Sanos } \\
\text { entrenamiento }\end{array}$ & 160 \\
\hline $\begin{array}{l}\text { Inmaduros } \\
\text { validación }\end{array}$ & 128 & $\begin{array}{l}\text { Inmaduros } \\
\text { entrenamiento }\end{array}$ & 100 & $\begin{array}{l}\text { Dañados } \\
\text { entrenamiento }\end{array}$ & 80 \\
\hline \multicolumn{1}{|c|}{ Total } & 360 & Validación & Tañados & 40 \\
validación & Total & 600 \\
\hline
\end{tabular}

Fuente: Elaboración propia 
Los conjuntos de datos de imágenes digitales han sido clasificados considerando que el corte del durazno implica detectar el fruto maduro y cortar. Sin embargo, cuando el fruto está dañado, debería cortarse pero separarse de los frutos sanos y maduros. Los frutos no maduros deberían de no cortarse hasta que alcancen su madurez.

\section{Modelo}

La CNN utilizada tiene tres capas con filtros de $2 \times 2$ y de $3 \times 3$. Las primeras dos capas incluyen acción de pooling. La CNN tiene como entrada las imágenes de los data set. En la salida, se obtienen los datos de la clasificación en dos o tres categorías. Se pueden ver los detalles en la figura 2.

Figura 2 Arquitectura de la CNN usada para el entrenamiento

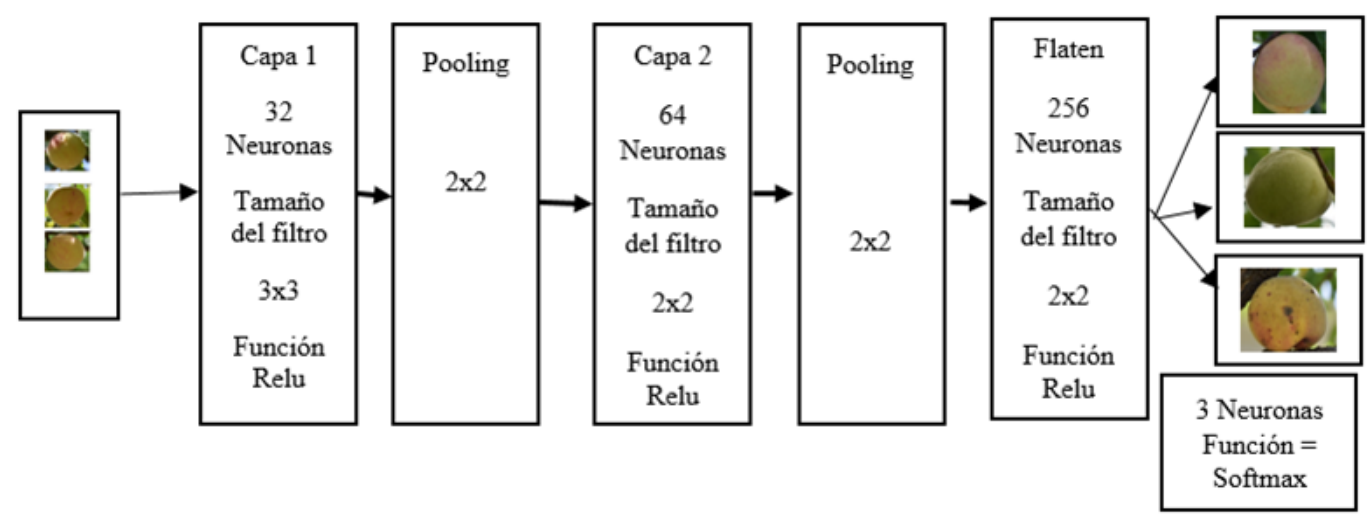

Fuente: Elaboración propia

La capa uno tiene 32 neuronas de $3 \times 3$ y se aplica la función Relu. En seguida, la capa dos cuenta con 64 neuronas de $2 \times 2$ y la función Relu. En tercer lugar, la capa Flaten incluye 256 neuronas, un filtro de $2 \times 2$ y la función Relu. Finalmente, la capa Dropout cuenta con tres neuronas y la función Softmax, lo que quiere decir que la categoría se clasifica con el valor más alto de similitud encontrado durante el reconocimiento.

Cabe señalar que, con 560 imágenes y 25 épocas, se hizo otra clasificación de duraznos: maduros, inmaduros y dañados. Después del entrenamiento, se hizo la prueba con 60 imágenes. 


\section{Resultados}

Se aplicó una prueba con 64 imágenes para cada caso. Se obtuvieron verdaderos positivos, verdaderos negativos, falsos positivos y falsos negativos, lo que permitió obtener otros indicadores relacionados con la precisión, la sensibilidad y la especificidad, ver la tabla 2.

Tabla 2. Resultados obtenidos durante las pruebas con 64 imágenes

\begin{tabular}{|c|c|c|c|c|c|c|}
\hline & \multicolumn{3}{|c|}{ Matriz de confusión } & Precisión & Sensibilidad & Especificidad \\
\hline \multirow{3}{*}{$\begin{array}{l}\text { Duraznos } \\
\text { maduros e } \\
\text { inmaduros }\end{array}$} & & Positivos & Negativos & \multirow[t]{3}{*}{95.31} & \multirow[t]{3}{*}{93.93} & \multirow[t]{3}{*}{96.77} \\
\hline & Positivos & 31 & 1 & & & \\
\hline & Negativos & 2 & 30 & & & \\
\hline \multirow{2}{*}{$\begin{array}{l}\text { Duraznos } \\
\text { maduros e } \\
\text { inmaduros } \\
\text { (textura) }\end{array}$} & Positivos & 25 & 7 & \multirow[t]{2}{*}{84.37} & \multirow[t]{2}{*}{89.28} & \multirow[t]{2}{*}{80.55} \\
\hline & Negativos & 3 & 29 & & & \\
\hline \multirow{2}{*}{$\begin{array}{l}\text { Duraznos } \\
\text { sanos y } \\
\text { dañados }\end{array}$} & Positivos & 31 & 1 & \multirow[t]{2}{*}{92.18} & \multirow[t]{2}{*}{88.57} & \multirow[t]{2}{*}{96.55} \\
\hline & Negativos & 4 & 28 & & & \\
\hline
\end{tabular}

Fuente: Elaboración propia

En los resultados se observa una precisión de $95.31 \%$ al clasificar duraznos maduros e inmaduros, es decir, que solo se clasifica mal 1 de 20 duraznos. Por otro lado, con las imágenes en las cuales solo se consideró la textura, se obtuvo un valor más bajo, 84.37 \%; esto quiere decir que se clasifican mal 3 de 20 duraznos. Finalmente, se obtuvo $92.18 \%$ al clasificar los duraznos sanos y dañados: al menos 2 de 20 duraznos se clasificarían mal.

A partir de la clasificación de tres categorías se obtuvo la matriz de confusión presentada en la tabla 3 . 
Tabla 3. Matriz de confusión de la clasificación de duraznos dañados, inmaduros y maduros.

\begin{tabular}{|l|l|l|l|}
\hline Duraznos & Dañados & Inmaduros & Maduros \\
\hline Dañados & 19 & 0 & 1 \\
\hline Inmaduros & 4 & 14 & 2 \\
\hline Maduros & 3 & 0 & 17 \\
\hline
\end{tabular}

Fuente: Elaboración propia

Durante el entrenamiento, en la clasificación de las tres categorías se obtuvo una precisión de $95.54 \%$. Mientras que durante las pruebas con 60 imágenes se obtuvo la precisión de $83.33 \%$, al dividir los verdaderos positivos de las tres categorías entre el total de unidades a clasificar. Esta clasificación resulta clave ya que el algoritmo debe de identificar el tipo de durazno una vez obtenida la imagen.

El comportamiento de la pérdida y de la precisión durante el entrenamiento de 25 épocas se puede ver en la figura 3.

Figura 3 Comportamiento de la pérdida de la precisión

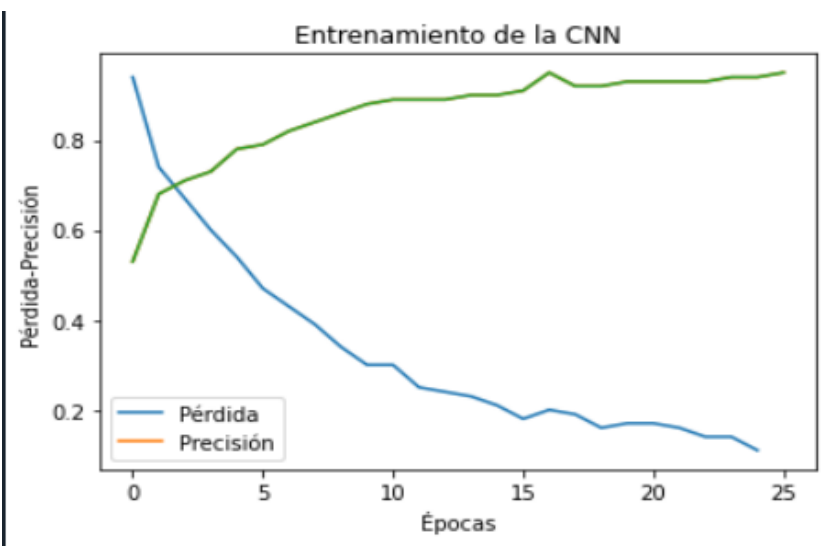

Fuente: Elaboración propia

Se puede observar una pérdida con tendencia a 0.0 , mientras que una precisión con tendencia a $100 \%$. 


\section{Discusión}

Las CNN tienen diversas áreas de aplicación. Sin embargo, independientemente del área, la solidez del conjunto de datos es esencial: debe ser resultado de una sistemática toma de imágenes en las condiciones óptimas de las características que se desean considerar como rasgos clasificatorios. También, el modelo de la CNN complementa la correcta identificación de intereses particulares en las imágenes. Como el entrenamiento de una CNN debe servir para casos reales, entonces el conjunto de datos debe tener características de balanceo, es decir, igual número de imágenes para los diferentes grupos a utilizar. De igual manera, la cantidad de imágenes para validación debe ser suficiente para evitar el sobreajuste o estandarización de imágenes de la CNN.

Aquí se obtuvo una precisión de $95.31 \%$ al clasificar duraznos maduros e inmaduros. Sin embargo, cuando se involucraron tres clases, a saber, maduros, no maduros y dañados, se obtuvo una precisión de $92.8 \%$. Es decir, a pesar de que el tercer grupo tenía muy explícitas sus características físicas dentro de las imágenes, fue un factor para que la precisión disminuyera considerablemente. Así pues, se deben realizar más investigaciones, aplicación de redes especializadas para que la clasificación de más de dos grupos tenga mejores resultados.

\section{Conclusión}

Después de analizar los resultados se puede concluir que la precisión sugiere que la clasificación aquí desarrollada se puede implementar en alguna máquina que pudiese cosechar duraznos de manera automatizada.

También es importante notar que las imágenes que solo muestran la textura del durazno empeoran los resultados, por lo que es mejor usar la imagen completa del durazno.

Clasificar las tres categorías mostró resultados aceptables, con una eficiencia de $83.33 \%$, lo que implica que acierta cuatro y falla una de cada cinco clasificaciones.

Cuando se trabaja con CNN es conveniente hacerlo con una gran cantidad de datos (data set de fotos) y así mejorar la precisión. Mientras más fotografías más probabilidades de aumentar la confiabilidad. 


\section{Futuras líneas de investigación}

El presente trabajo puede resultar de gran apoyo para nuevas investigaciones relacionadas con la clasificación de frutos al momento de la cosecha, o bien para la clasificación y aplicación de precios. Es importante señalar que las CNN tienen mejor desempeño con un mayor número de imágenes no controladas. Las imágenes pueden obtenerse de empresas, agricultores y más.

Ya atendida la clasificación del fruto del durazno entre maduros y no maduros, así como duraznos sanos y dañados, investigaciones futuras se enfocarán en algoritmos para clasificar por tamaño, dado que los frutos del durazno pueden tener diferentes dimensiones, y entre esa variedad el mercado puede requerir de ciertos tamaños mínimos. Así, se podrán discriminar los frutos que tienen un tamaño menor al aceptado por el mercado. La otra línea de investigación será la clasificación del fruto por la forma. Es sabido que el mercado puede llegar a rechazar los frutos que estén deformes, a pesar de cumplir con la madurez y el tamaño requeridos, entre otros factores, por lo que poder discriminar los frutos que no tengan la redondez que el estándar de calidad demanda sería de utilidad para los productores. Finalmente, como tercera línea de investigación, será tratar de generalizar el método y modelo para que sea capaz de funcionar con otros frutos. El conjunto de algoritmos podría incorporarse a una máquina clasificadora de frutas con solo ajustar los parámetros de clasificación. La aplicación de las CNN es infinita. 


\section{Referencias}

Alipasandi, A., Ghaffari, H. and Zohrabi, A. S. (2013). Classification of Three Varieties of Peach Fruit Using Artificial Neural. International Journal of Agronomy and Plant $\begin{array}{llll}\text { Production, } & 4(9), & \text { 2179-2186. } & \text { Retrieved }\end{array}$ https://www.researchgate.net/publication/318878038_Classification_of_three_varie ties_of_peach_fruit_using_artificial_neural_network_assisted_with_image_process ing_techniques.

Amlekar, M., Manza, R. R., Yannawar, P. and Gaikwad, A. T. (2014). Leaf Features Based Plant Classification Using Artificial Neural Network. IBMRD's Journal of Management and Research, 3(1), 224-232.

Baíza, V. H. (2004). Guía técnica del cultivo del melocotón. El Salvador: Ministerio de $\begin{array}{llll}\text { Agricultura } & \text { y } & \text { Ganadería. }\end{array}$ http://repiica.iica.int/docs/B0220e/B0220e.pdf.

Cervantes, J., Taltempa, J., García, F., Ruiz, J. S., Yee, A. y Jalili, L. D. (2017). Análisis comparativo de las técnicas utilizadas en un sistema de hojas de planta. Revista Iberoamericana de Automática e Informática Industrial, 14(1), 104-114. Recuperado de http://dx.doi.org/10.1016/j.riai.2016.09.005.

Hati, S. and G, S. (2013). Plant Recognition from Leaf Image through Artificial Neural Network. International Journal of Computer Applications, 62(17), 15-18.

Heyan, Z., Qinglin, L. and Yuankai, Q. (2018). Plant identification based on very deep convolutional. Multimedia Tools and Applications, 77, 29779-29797. Retrieved from https://doi.org/10.1007/s11042-017-5578-9.

Kadir, A., Nugroho, L., Susanto, A. and Insap, P. (2011). Leaf Classification Using Shape, Color, and Texture Features. International Journal of Computer Trends and Technology, $225 \quad-\quad 230 . \quad 2 \quad$ Recuperado de https://www.researchgate.net/publication/224954034_Leaf_Classification_Using_S hape_Color_and_Texture_Features.

Krizhevsky, A., Sutskever, I. and Hinton, G. (2012). ImageNet Classification with Deep Convolutional Neural Networks. Paper presented at the $25^{\text {th }}$ International Conference on Neural Information Processing Systems. 
Ma, J., Keming, D., Zhenga, F., Zhang, L., Gong, Z. and Sun, Z. (2018). A recognition method for cucumber diseases using leaf symptom images based on deep convolutional neural network. Computers and Electronics in Agriculture, 154, 1824.

Morris, D. D. (2018). A Pyramid CNN for Dense-Leaves Segmentation. Paper presented at the $15^{\text {th }}$ Conference on Computer and Robot Vision. Toronto, May 9-11, 2018. Retrieved from https://arxiv.org/pdf/1804.01646.pdf.

Sharpe, S. M., Schumann, A. W. and Boyd, N. S. (2019). Detection of Carolina Geranium (Geranium carolinianum) Growing in Competition with Strawberry Using Convolutional Neural Networks. Weed Science, 67(2), 239-245.

Simonyan, K., \& Zisserman, A. (2015). Very Deep Convolutional Networks for Large Scale Image Recognition. ICLR. 


\begin{tabular}{|l|l|}
\hline Rol de Contribución & Autor (es) \\
\hline Conceptualización & Sergio Ruíz \\
\hline Metodología & Dolores Arévalo, Sergio Ruíz \\
\hline Software & Dolores Arévalo, Sergio Ruíz \\
\hline Validación & Dolores Arévalo, Sergio Ruíz \\
\hline Análisis Formal & Dolores Arévalo, Sergio Ruíz \\
\hline Investigación & Dolores Arévalo \\
\hline Recursos & Dolores Arévalo \\
\hline Curación de datos & Dolores Arévalo \\
\hline $\begin{array}{l}\text { Escritura - Preparación del } \\
\text { borrador original }\end{array}$ & Dolores Arévalo \\
\hline $\begin{array}{l}\text { Escritura - Revisión y } \\
\text { edición }\end{array}$ & Dolores Arévalo, Sergio Ruíz, Joel Ayala \\
\hline Visualización & Dolores Arévalo, Sergio Ruíz, Joel Ayala \\
\hline Supervisión & Sergio Ruíz, Joel Ayala \\
\hline Administración de Proyectos & Sergio Ruíz, Joel Ayala \\
\hline Adquisición de fondos & Dolores Arévalo \\
\hline
\end{tabular}

